Proceedings

\title{
Sustainable Urbanisation: An Ecosystems Approach towards Future Cities
}

1 Research Scholar, MNIT Jaipur

2 Associate Professor, MNIT Jaipur

3 Assistant Professor, MNIT Jaipur

* Correspondence: anjalisaraswat7@gmail.com; Tel.: +91-8802707584

\begin{abstract}
Cities are dynamically changing with the rapid pace of urbanisation. India being a developing nation has an ever-increasing number of mega cities. What follows this unprecedented rate of urbanisation is not only economic and industrial growth but also deteriorating urban quality of life. Thus, emergence of sustainable urbanisation in cities is an extreme requisite in order to gain environmental equity. Ecosystems approach allows restoring of the ecosystem component within cities and embedded with the urban planning process yields sustainable urbanisation. The research paper develops an urban sustainability evaluation framework to guide sustainable urbanisation and assists the decision-making process.
\end{abstract}

Keywords: ecosystems approach; ecosystems services; sustainable urbanization; urban ecology; urban planning

\section{Introduction}

The world today is becoming a global village with rapid globalization and Citation: Saraswat, A.; Pipralia, S.; Kumar, A., 2022, Sustainable Urbanisation: An Ecosystems Approach towards Future Cities. SUPTM 2022 conference proceedings sciforum054492 .

https://doi.org/10.31428/10317/10591

Publisher's Note: UPCT and Sciforum stays neutral with regard to jurisdictional claims in published maps and institutional affiliations.

\section{(i)}

Copyright: (c) 2022 by the authors. Submitted for possible open access publication under the terms and conditions of the Creative Commons Attribution (CC BY) license (https://creativecommons.org/license s/by/4.0/). integration of markets making cities emerge as an engine of growth. There is a global rise in population in cities. In 1980 the worldwide urban population was 1.73 billion, with 3.98 billion in 2015 and is projected to rise to 6.49 billion by 2050. Much of the population rise is anticipated to occur in developing countries of Asian and African continents. The cities in Asia are projected to account for large portions of global urban cover. Indian cities are projected to have a population rise of 400 million by the year 2050. This urban growth leads to an increase in built up areas in cities to assist population accommodation mostly. In developing countries, the scenarios of urban development are usually rapid, haphazard, informal and unplanned leading to irreversible impacts on the environment. With this occurs the loss of agricultural land, decline in biodiversity and reduction in various ecosystem services.

In India the cities are growing demographically and spatially. Within the past 5 decades the urban population has had an addition of 7 to 8 million people every year with the increase in level of urbanisation from $11 \%$ to $20 \%$ in the first three decades and $17.3 \%$ in 1951 to $25.7 \%$ in 1991 and currently being $34.03 \%$. The number of cities has increased from 5161 in 2001 to 7935 in 2011 and this number is projected to speed up in the near future. Presently there are seven mega cities in the country with a population of more than 4 million. This increase in the number of urban centres is followed by a rising urban population. The country is facing unprecedented urbanisation along with economic 
growth and industrialisation. Thus, cities are enjoying the virtues of both economic and social development but at the same time are becoming congested centres of environmental degradation. Concentration of population in few cities has been the characteristic feature of urbanisation in India leading to merciless deterioration of quality of life. With this rapid urbanisation in the country the prime agricultural land is being converted to urban use especially at city peripheries. Along with this inaccessibility to land for new population in cities is observed contributing to unauthorized and haphazard development. Such a rise in population in cities is contributing to high densities and eventually adversely impacting natural and environmental resources.

Thus the need of the hour is to explore concepts and theories which would promote sustainable development within our cities leading to limiting the energy consumption, reduced pollution levels, protection of natural environments and overall better quality of life for urban citizens.

\section{Ecosystem's approach}

Urban ecosystems are the cities comprising human communities interacting with surrounding social ecological systems such as biodiversity, soil, hydrology, climate and various flows of matter and energy (see figure 1). The concept of sustainable development was first introduced in the world commission on Environment and Development report stating that "sustainable development means meeting the needs of the present without compromising the needs of the future generations". Sustainable development in urban settings can be set up by the ecosystems approach, which is a strategic framework for taking account of ecosystem services while decision-making (United Nations, 2011). The ecosystem approach intends to restore the ecosystem components within our urban centres and integrate environmental equity concerns during the urban planning process(Berkowitz et al., 2006; Geneletti et al., 2019).

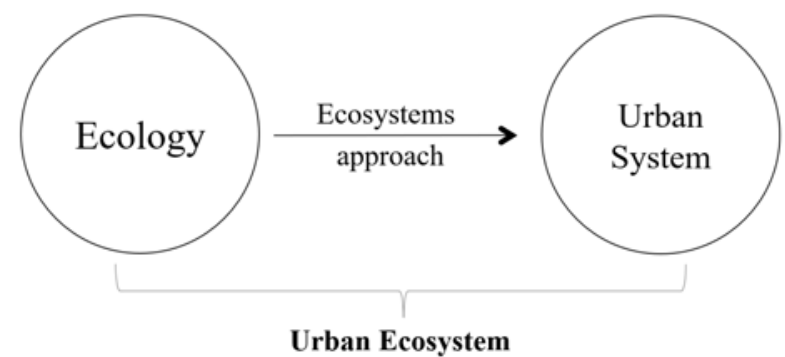

Figure 1. The concept of ecosystems approach

A compact urban morphology is promoted for cities which would escalate the walkability among the communities as well as drop down pollution levels via reducing automobile leaves. In the process transit-oriented development is conceptualized for urban centres bringing citizens, their associated activities, built up as well as public spaces together. Prioritising the ecosystem approach for sustainable urbanisation of our future cities in current times is an outcome of several efforts by the international and national organisations to address the issue of ecological degradation. To ensure the sustainability of various resources concrete efforts to develop ecosystems approach framework and their

1 2 
integration in legislation through policy and programs is required. The consequential outcomes of the ecosystems approach in planning future cities can be observed through several environmental, economic and social benefits. Better quality of life of city dwellers, improved health, water and other resources as well as reduced urban sprawl and traffic congestion are few of the outcomes of using ecosystems approach.

\section{Sustainability evaluation through ecosystems approach}

Assimilating sustainable urbanisation requires strategic measures involving ecosystems approach in the decision-making process, which can be realised via numerous urban sustainability evaluation techniques (Rieckmann \& Marco, 2017). These techniques provide guidelines at local, regional and national scale for assessing sustainability. The developed urban sustainability evaluation framework defines urban sustainability goals as well as does timely appraisal of the progress made by these goals in the urban settings. Executing through analysis of the contemporary urban planning practices along with comparing performance evaluation in various sectors, amendments are suggested. Future urban sustainability scenarios are also planned based on the evaluation (Azapagic \& Perdan, 2011).

The urban sustainability evaluation framework suggested in the paper focuses largely on the involvement of various stakeholders of urban settings (see figure 2). Feedbacks taken from researchers, modellers, practitioners and decision makers are incorporated in the evaluation process. A comprehensive, standardizing and procedural practice within the urban planning process to attain sustainable urbanisation is brought forth through the framework keeping the multi-dimensional viewpoint of the urban system. The first step in the urban sustainability evaluation framework is to analyse the existing system by the identification of study areas where sustainable urbanisation goals need to be applied. Identifying the spatial limits such as municipal wards, planning zones allows efficient data collection of geographical, topographical, demographical, economic and various other related aspects. Next step in the framework is to identify the stakeholders vital to the urban system which involves locating the communities largely affected by the urbanisation process, as well as enlisting various practitioners working with the on-ground situation. Also, insightful viewpoints in the process are attained via several experts' inputs. Defining the scope of the problem is the step that follows allowing to choose the requisite variable for the study from the multivariate list of factors affecting urban sustainability. Setting out sustainability vision is done next, by evolving the evaluation criteria based upon prime guiding principles. The objectives for sustainable urbanisation are set out and further policy scenarios are based upon the urban sustainability vision. In the succeeding step appropriate model is selected and simulation of the collected data is done through suitable agent-based modelling techniques. The data collected and modelled is quantified to give empirical results. Assessment of the database is done at the last stage where the scenarios are understood and results concluded. Based on these assessments, policy guidelines for sustainable measures are given. Setting out sustainability vision is done next, by evolving the evaluation criteria based upon prime guiding principles. The objectives for sustainable urbanisation are set out and further 
policy scenarios are based upon the urban sustainability vision. In the succeeding step appropriate model is selected and simulation of the collected data is done through suitable agent-based modelling techniques. The data collected and modelled is quantified to give empirical results. Assessment of the database is done at the last stage where the scenarios are understood and results concluded. Based on these assessments policy guidelines for sustainable measures are given.

Urban Sustainability Evaluation Framework

\begin{tabular}{|c|}
\hline Analysing existing system \\
\hline Identifying stakeholders \\
\hline Defining scope \\
\hline Setting sustainability vision \\
\hline Appropriate model selection \\
\hline Assessment of database \\
\hline
\end{tabular}

Figure 2. Steps involved in Urban Sustainability Evaluation Framework

\section{Conclusion}

Sustainable cities make the quality of life of citizens better. They build upon the economic prosperity of the region by strategic use of natural resources, as well as safeguards the environment by protecting biodiversity. The process of sustainable urbanisation requires the use of measures and approaches which are based upon ecological principles so as to yield maximum benefits offered by the environment and incorporating ecosystems approach in the urban planning process is one such way. Framework developed in this research paper provides a step-by-step procedure to follow to incorporate sustainable urbanisation in our cities. With stakeholder involvement at each step the ultimate outcome of the framework comes practically viable. Future research scenarios involving the detailed description and analysis of each step by the framework can be developed.

\section{References}

$$
\text { description and analysis of each step by the framework can be developed. }
$$

1. Azapagic, A., \& Perdan, S. (2011). Sustainable Development in Practice: Case Studies for Engineers and Scientists. John Wiley \& Sons.

2. Berkowitz, A. R., Nilon, C. H., \& Hollweg, K. S. (2006). Understanding Urban Ecosystems: A New Frontier for Science and Education. Springer Science \& Business Media.

3. Geneletti, D., Cortinovis, C., Zardo, L., \& Esmail, B. A. (2019). Planning for Ecosystem Services in Cities. Springer.

4. Rieckmann, \& Marco. (2017). Education for Sustainable Development Goals: learning objectives. UNESCO Publishing.

5. United Nations. (2011). Shanghai Manual: A Guide for Sustainable Urban Development in the 21st Century. 